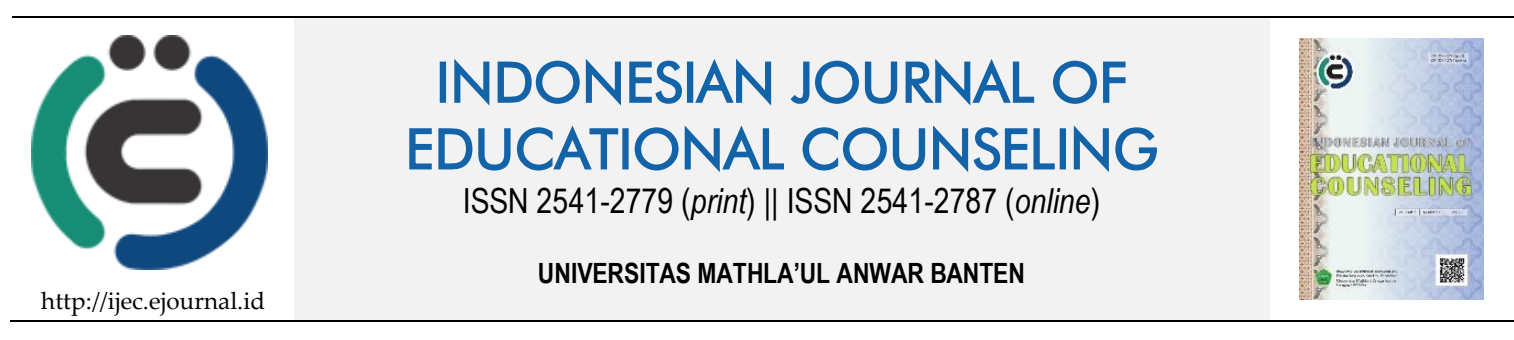

Research Based Article

\title{
Tingkat Penyesuaian Sosial Anak Asuh di Panti Asuhan Wira Lisna
}

\author{
Imalatul Khairat ${ }^{1}$, Peni Ramanda ${ }^{2}$, Yogi Damai Syaputra ${ }^{2}$
}

1, 2 Universitas Islam Negeri Sultan Maulana Hasanuddin Banten

\begin{tabular}{|c|c|}
\hline Article History & ABSTRACT \\
\hline $\begin{array}{l}\text { Received: } 26.11 .2020 \\
\text { Received in revised form: } \\
18.12 .2020 \\
\text { Accepted: } 07.01 .2021 \\
\text { Available online: } 29.01 .2021\end{array}$ & $\begin{array}{l}\text { THE LEVEL OF SOCIAL ADJUSTMENT OF FOSTER CHILDREN AT THE } \\
\text { WIRA LISNA ORPHANAGE. This study aims to reveal the conditions of social } \\
\text { adjustment of foster children in the orphanage. This research uses quantitative } \\
\text { methods. The data were collected through a social adjustment scale that the } \\
\text { author developed himself with a reliability of } 0.936 \text {. The sample of this research } \\
\text { is } 10 \text { foster children at the Wira Lisna orphanage in the city of Padang. The data } \\
\text { analysis used in this research is descriptive statistics. The results of this study } \\
\text { reveal that the level of social adjustment of Wira Lisna Padang's anti-care foster } \\
\text { children is in the unfavorable category. The results of this study can be used as } \\
\text { a basis for determining the next step in order to improve the social adjustment } \\
\text { ability of foster children at the Wira Lisna orphanage, Padang. The intervention } \\
\text { efforts provided can be tailored to the researcher's area of expertise. }\end{array}$ \\
\hline & KEYWORDS: Foster Children Orphanages, Social Adjustment. \\
\hline
\end{tabular}

DOI: $10.30653 / 001.202151 .151$

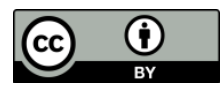

This is an open access article distributed under the terms of the Creative Commons Attribution 4.0 International License, which permits unrestricted use, distribution, and reproduction in any medium, provided the original work is properly cited. c 2021 Imalatul Khairat, Peni Ramanda, Yogi Damai Syaputra.

\section{PENDAHULUAN}

Kasih sayang dari orang tua adalah hal yang paling diimpikan oleh setiap anak. Bagitu juga dengan anak-anak di panti asuhan. Kebanyakan di antara mereka tidak mendapatkan kasih sayang yang penuh dari orang tuanya, hal ini ditandai dengan hadirnya mereka di panti asuhan. Banyak hal yang menjadi faktor penyebab anak-anak terpaksa harus tinggal di panti asuhan yang membuat mereka berjauhan dari orang-orang yang disayang, seperti kehilangan ibu atau ayah, ditinggalkan oleh keluarga dan ketidakmampuan ekonomi keluarga. Faktor inilah yang memaksa mereka untuk tinggal di panti asuhan demi kelangsungan kehidupan yang lebih layak. Mereka yang tinggal di panti asuhan kebanyakan diisi oleh anak yang berada pada kegori remaja. Para remaja akan banyak menghabiskan waktu dengan teman sebayanya (Syaputra, 2018). Mereka akan merasa lebih nyaman ketika mereka berada dalam komunitasnya. Ini memerlukan keterampilan untuk melakukan penyesuaian sosial di lingkungan panti asuhan. Kemampuan dalam menyesuaiakan diri di lingkungan sosial merupakan salah satu aspek

${ }^{1}$ Corresponding author's address: Program Studi Bimbingan Konseling Islam, Fakultas Dakwah, Universitas Islam Negeri Sultan Maulana Hasanuddin Banten; Jl. Sudirman No 30, Serang, Banten, Indonesia. Email: imalatul.khairat@uinbanten.ac.id 
dalam tugas perkembangan pada remaja. Di usia ini mereka dituntut untuk bisa melakukan penyesuaian sosial dengan lingkungan disekitarnya. Berhasilnya mereka dalam penyesuaian sosial akan berdampak terhadap perkembangannya.

Suasana baru yang dirasakan anak asuh dipanti asuhan sering kali membuat mereka tidak mampu dalam menyesuaikan diri. Anak asuh banyak yang berasal dari kondisi dan daerah yang berbeda-beda. Lingkungan yang mereka hadapi selama di luar panti akan berbeda setelah mereka berada di dalam panti asuhan. Etika berkomunikasi, pola pergaulan dan ketidakmampuan untuk menyesuaikan diri di lingkungan sosial panti asuhan. termasuk kedalam permasalahan yang sering terjadi di panti asuhan. Masalah penyesuaian sosial merupakan permasalahan yang perlu untuk diatasi dilingkungan panti asuhan. Penelitian Khairat, Firman, \& Neviyarni (2018) masih banyak terdapat anak asuh yang tidak mampu menjalani tanggung jawab dan kewajiban sesuai dengan peraturan yang diterapkan di panti, sering bertengkar, merasa rendah diri, tertutup, masih ada yang kurang peduli terhadap permasalahan teman, merasa minder dengan teman-teman yang tinggal bersama orangtua mereka, kesulitan dalam menerima kondisi diri yang sekarang, serta masih terdapat anak asuh yang tidak menghargai warga panti khususnya menghargai pengasuh.

Schneiders (1964) menyatakan individu dalam penyesuaian sosial harus bisa menyeimbangkan antara pemenuhan kebutuhan diri sendiri dengan kebutuhan eksternal yang dapat diihat dari adanya kemampuan menjalin hubungan yang positif dengan orang lain, berpartisipasi aktif dalam kelompok sosial, memiliki minat sosial, dan adanya kepuasan dalam melakukan aktivitas. Individu yang mampu memenuhi kebutuhan ini secara langsung akan dapat diterima oleh lingkungan sosialnya. Hal ini juga berlaku dalam lingkungan panti asuhan. Anak yang mampu menjalin hubungan yang baik dengan temannya di panti asuhan maka akan dapat diterima dengan baik oleh warga panti. Penyesuaian sosial bagi seseorang akan terus terjadi secara berkelanjutan, karena diri dan lingkungan menjadi sebuah realitas yang tidak dapat dipungkiri akan menjadi satu kesatuan. Penyesuaian sosial terhadap lingkungan, seseorang individu harus memperhatikan dan mengenal berbagai norma yang berlaku di dalam lingkungan masyarakat atau mematuhi aturan yang berlaku (Sunarto \& Hartono, 2013).

Adapun yang menjadi indikator penyesuaian sosial adalah: (1) hubungan yang sehat dengan anggota keluarga, (2) kesediaan menerima dan menjalankan aturan, (3) memikul tanggung jawab dan menerima batasan, (4) membantu keluarga untuk mencapai tujuan bersama, dan (5) kebebasan yang terarah (Schneiders, 1964). Bagi anak panti asuhan, warga panti dan bapak-ibu serta kakak pengasuh adalah keluarga mereka. Anak-anak asuh lebih banyak menghabiskan waktu dengan mereka. Oleh karena itu sebagai upaya dasar yang dapat dilakukan adalah dengan meninjau profil sejauhmana tingkat penyesuaian sosial anak-anak di panti asuhan.

\section{METODE}

Penelitian ini menggunakan metode deskriptif kuantitatif. Metode ini bertujuan untuk mendeskripsikan data yang diperoleh atau menggambarkan kondisi factual (Sugiyono, 2014). Penelitian ini bertujuan untuk mengukur tingkat penyesuaian sosial anak asuh di panti asuhan. Panti asuhan Wira Lisna Padang menjadi lokasi penelitian. Populasi dalam penelitian seluruh anak yang ada di panti asuhan dalam kategori remaja. Sampel dalam penelitian ini adalah 10 orang remaja. Data di peroleh melalui instrumen skala penyesuaian sosial yang terdiri dari 41 item dengan reliabilitas alpha cronbach 
sebesar 0.936 . Secara rinci skala penyesuaian sosial terdiri dari 5 sub-variabel, diantaranya 9 item pernyataan dengan sub-variabel Hubungan yang Sehat dengan Anggota Panti, 7 item pernyataan dengan sub-variabel Kesediaan Menerima dan Menjalankan Aturan Panti, 8 item pernyataan dengan sub-variabel Memikul Tanggung Jawab dan Menerima Batasan, 10 item pernyataan dengan sub-variabel Membantu Keluarga di Panti untuk Mencapai Tujuan Bersama, dan 7 item pernyataan dengan sub-variabel Kebebasan yang Terarah dari Keluarga di Panti. Adapun cara yang digunakan untuk menentukan rentanag skor adalah sebagai berikut:

$$
\text { Interval } k=\frac{\text { Skor Tertinggi }- \text { Skor Terendah }}{\text { jumlah } \text { kelompok }}
$$

Gambar 1. Rumus Interval

Sumber: (Irianto, 2010)

Data akan di analisis dengan mengunakan deskiptif statistik menggunakan SPSS versi 21.00. Untuk menggambil keputusan tingkat penyesuaian sosial anak panti digunakan kategori sebagai berikut:

Tabel 1. Kategori Tingkat Penyesuaian Sosial

\begin{tabular}{ll}
\hline Skor & Kategori \\
\hline $173-205$ & Sangat Baik \\
\hline $140-172$ & Baik \\
\hline $107-139$ & Cukup Baik \\
\hline $74-106$ & Kurang Baik \\
\hline $41-73$ & Tidak Baik \\
\hline
\end{tabular}

\section{HASIL DAN PEMBAHASAN}

Hasil penelitian diperoleh melalui penyebaran instrument yang diberikan kepada anak-anak di panti asuhan wira lisna Padang. Berdasarkan penelitian diperoleh hasil pada Tabel 2

Tabel 2. Kondisi Penyesuaian Sosial Anak Asuh di Panti Asuhan Wira Lisna Padang

\begin{tabular}{llll}
\hline No & Inisial Responden & Skor & Kategori \\
\hline 1 & AR & 104 & Kurang Baik \\
\hline 2 & NH & 111 & Cukup Baik \\
\hline 3 & UH & 112 & Cukup Baik \\
\hline 4 & NY & 103 & Kurang Baik \\
\hline 5 & ER & 104 & Kurang Baik \\
\hline 6 & MP & 118 & Cukup Baik \\
\hline 7 & SE & 102 & Kurang Baik \\
\hline 8 & VO & 103 & Kurang Baik \\
\hline 9 & SF & 101 & Kurang Baik \\
\hline 10 & AZ & 102 & Kurang Baik \\
\hline Jumlah & 1060 & \\
\hline Rata-rata & 106 & Kurang Baik \\
\hline
\end{tabular}


Berdasarkan hasil di atas diperoleh tingkat penyesuaian sosial anak di panti asuhan wira lisna berada pada kegori kurang baik dengan skor rata-rata sebesar 106 berada pada rentang skor. Berdasarkan hasil tersebut terungkap bahwa dari 10 orang anak di panti asuhan hanya 3 (tiga) anak yang penyesuaian sosialnya berada pada ketegori cukup dan 7 orang pada kategori kurang baik. Berikut akan dijelaskan secara rinci hasil skor penyesuaian sosial berdasarkan indikator penelitian.

Tabel 3. Kondisi Penyesuaian Sosial Berdasar Sub-Variabel

\begin{tabular}{lllllll}
\hline \multirow{2}{*}{ No } & Inisial & Sub & Sub & Sub & Sub & Sub \\
& Responden & Variabel I & Variabel II & Variabel III & Variabel IV & Variabel V \\
\hline 1 & AR & 21 & 21 & 23 & 26 & 19 \\
\hline 2 & NH & 31 & 25 & 29 & 36 & 22 \\
\hline 3 & UH & 25 & 19 & 23 & 24 & 17 \\
\hline 4 & NY & 40 & 28 & 26 & 41 & 21 \\
\hline 5 & ER & 32 & 30 & 29 & 42 & 24 \\
\hline 6 & MP & 34 & 33 & 33 & 42 & 30 \\
\hline 7 & SE & 26 & 20 & 24 & 33 & 18 \\
\hline 8 & VO & 31 & 23 & 32 & 29 & 17 \\
\hline 9 & SF & 31 & 26 & 32 & 31 & 17 \\
\hline 10 & AZ & 25 & 22 & 25 & 29 & 16 \\
\hline Jumlah & 296 & 247 & 276 & 333 & 201 \\
\hline
\end{tabular}

Pada sub-variabel pertama terkait hubungan sehat dengan anggota panti memiliki jumlah 296, kemudian pada sub variabel kedua kesediaan menerima dan menjalankan aturan panti diperoleh jumlah sebesar 247. Sub-variabel ketiga memikul tanggung jawab dan menerima batasan diperoleh jumlah skor 276. Pada sub-variabel keempat, membantu keluarga di panti untuk mencapai tujuan bersama diperoleh skor sebesar 333 dan subvariabel kelima, kebebasan yang terarah dari keluarga di panti diperoleh jumlah skor sebesar 201. Berikutnya data ini akan dilakukan uji analisi deskriptif statistik sehingga diperoleh hasil pada Tabel 4 .

Tabel 4. Deskriptif Statistik

\begin{tabular}{llllll}
\hline & $\mathrm{N}$ & Minimum & Maximum & Mean & Std. Deviation \\
\hline Sub_Variabel_1 & 10 & 21 & 40 & 29.60 & 5.461 \\
\hline Sub_Variabel_2 & 10 & 19 & 33 & 24.70 & 4.572 \\
\hline Sub_Variabel_3 & 10 & 23 & 33 & 27.60 & 3.893 \\
\hline Sub_Variabel_4 & 10 & 24 & 42 & 33.30 & 6.667 \\
\hline Sub_Variabel_5 & 10 & 16 & 30 & 20.10 & 4.332 \\
\hline Valid N (listwise) & 10 & & & & \\
\hline
\end{tabular}

Berdasarkan Tabel 4 diketahui rata-rata untuk sub varibel 1 sebesar 29.60. Subvariabel 2 Sebesar 24.70. Sub-variabel 3 sebesar 27.60. Sub-variabel 4 sebesar 33.30 dan sub-variabel 5 sebesar 20.10. Hasil ini menggambarkan kurang baiknya kondisi anak asuh dalam menyesuaiakan diri di lingkungan sosial panti asuhan. Berdasarkan hasil 
penelitian ini, terungkap bahwa penyesuaian sosial remaja di panti asuhan Wira Lisna kota Padang berada pada kategori kurang baik. Hal ini menjadi perhatian khusus bagi banyak pihak. Banyak hal yang menyebabkan rendahnya penyesuaian sosial anak di panti asuhan. Menurut Schneiders (1964) ada beberapa kondisi yang menyebabkan rendahnya penyesuaian sosial diantaranya kondisi fisik, kematangan dan perkembangan, kondisi psikologis, kondisi lingkungan sosial dan budaya. Anak asuh di panti asuhan Wira Lisna Padang berada pada rentang usia remaja awal. Pada fase ini merupakan fase yang penuh dengan perubahan yang terjadi dalam diri seseorang. terjadinya perubahan kondisi fisik tubuh, terjadinya perubahan emosi yang tidak stabil dan lain sebagainya.

Ditinjau dari masing-masing sub variabel, pada sub-variabel hubungan yang sehat dengan anggota panti terungkap bahwa anak asuh masih memiliki sikap acuh tak acuh, tidak mau berbagi dengan teman atau kepala panti, masih adanya rasa kecemburuan, rasa benci dan permusuhan anatar anak asuh. Kondisi inilah yang membuat mereka tidak bisa menjalin hubungan yang sehat di lingkungan panti. Kemudian pada sub-variabel kesediaan menerima dan menjalankan aturan panti. Studi empiris menunjukkan bahwa anak-anak yang paling mudah menyesuaikan diri adalah mereka yang memiliki sikap disiplin terhadap pendapat orangtua dalam hal ini adalah orang tua asuh di panti asuhan. Namun berdasarakan analisis dari masing-masing butir item terungkap bahwa masih ada anak yang suka melanggar aturan yang sudah ditetapkan oleh panti.

Kemudian sub-variabel memikul tanggung jawab dan menerima batasan terungkap bahwa masih ada anak asuh yang belum bisa menerima kondisi keterbatasan fisik panti asuhan. Anak asuh banyak yang tidak sadar akan peran dan tanggunjawabnya. Pada subvariabel membantu keluarga di panti untuk mencapai tujuan bersama. Tujuan sebuah panti asuhan akan dapat dicapai dengan adanya kerjasama semua warga panti. Saling membantu anggota keluarga di panti dalam mencapai tujuan individu dan kelompok, dalam hal keberhasilan di sekolah, tujuan kejuruan, aspirasi agama, kegiatan rekreasi, dan sejenisnya. Sub-variabel kebebasan yang terarah dari keluarga di panti merupakan kebebasan pada anak dalam mencapai kepuasan berinteraksi di luar lingkungan keluarga panti. Kasih sayang keluarga, kehangatan, penerimaan, dan rasa memiliki yang diperlukan dan bermanfaat bagi kehidupan keluarga yang sehat.

Surya, (2003) menjelaskan kategori mekanisme penyesuaian sosial sebagai berikut: Penyesuaian sosial yang baik (well adjustment), seperti; pengendalian emosional yang baik, mampu mengarahkan diri dengan pertimbangan yang rasional, serta memiliki penghargaan diri yang tinggi. Kemudian penyesuaian diri yang salah (maladjustment), seperti; tingkah laku salah suai, tidak mampu mengendalikan emosi, tidak realistis serta bertingkah laku yang agresif, dan yang terakhir adalah penyesuaian yang patologis (pathologic adjustment). Adapun faktor yang mempengaruhi proses penyesuaian sosial individu, yaitu: kondisi fisik, meliputi: hereditas dan bentuk fisik, sistem utama tubuh, dan kesehatan fisik. Faktor yang selanjutnya adalah kepribadian, meliputi: kemampuan untuk berubah (modifiability), pengaturan diri (self-regulation), realisasi diri (selfrealization), dan intelegensi. Selain dari fisik dan kepribadian, faktor pendidikan, lingkungan, agama dan budaya seperti, belajar, pengalaman, latihan, determinasi diri, lingkungan keluarga, lingkungan sekolah, dan lingkungan masyarakat juga menjadi faktor yang mempengaruhi penyesuaian sosial individu (Schneiders, 1964).

Pada masa remaja penyesuaian sosial menjadi permasalahan yang sering dihadapi. Pada masa ini biasanya remaja akan dihadapkan pada situasi kehausan sosial (Danim, 2013). Selanjutnya (Hartati \& Respati, 2012) menjelaskan bahwa anak asuh yang menjalin 
hubungan dengan orang lain secara kaku, perkembangan, dan penyesuaian sosial yang kurang memuaskan menjadi hambatan dalam perkembangan kemampuan penyesuaian sosial dan perkembangan psikologisnya.

Sundari (2005) menjabarkan bahwa cirri inidividu memiliki kemampuan penyesuaian sosial yang positif adalah sebagai berikut; tidak adanya ketegangan emosi. Dalam hal memecahkan masalah, individu yang memiliki kemampuan penyesuaian sosial yang positif cenderung memiliki pertimbangan rasional, mengarah pada masalah yang dihadapi secara langsung dan mampu menerima segala akibatnya. Ciri selanjutnya adalah mampu bersikap realistis dan objektif. Mempelajari ilmu pengetahuan yang mendukung apa yang dihadapi, sehingga dengan pengetahuan itu dapat digunakan untuk menanggulangi timbulnya masalah. Ciri-ciri penyesuaian sosial yang positif juga dapat terlihat dari kesanggupan individu membandingkan pengalaman diri sendiri maupun pengalaman orang lain, yang berguna untuk membantu memecahkan masalahnya.

Lawton (dalam Hurlock, 2014) juga menjelaskan ciri-ciri yang dapat digunakan untuk mendeskripsikan individu mampu melakukan penyesuaian sosial yang baik, diantaranya adalah: dapat dilhat dari inidividu yang mampu dan bersedia menerima tanggung jawab sesuai dengan usia, melakukan partisipasi dengan gembira dalam kegiatan yang diikuti, menangani masalah yang menuntut penyelesaian secara cepat dan bijaksana, menyelesaikan masalah dan hambatan yang merusak kebahagiaan. Kemampuan dalam mengambil keputusan secara mandiri dan menghindari konflik. Belajar dari kegagalan dan tidak menyalahkan kegagalan dimasa lalu. Individu yang mampu menyesuaiakan diri di lingkungan sosial tentunya dapat menunjukkan kasih sayang secara langsung, dapat menahan sakit dan frustasi emosional yang berlebihan, dapat memusatkan energi pada tujuan yang penting, dan cirri yang terakhir adalah menerima kenyataan bahwa hidup adalah perjuangan yang tidak pernah berakhir.

\section{SIMPULAN}

Temuan hasil penelitian menunjukkan bahwa kemampuan anak asuh dalam melakukan penyesuaian sosial di panti asuhan Wira Lista Padang berada dalam kategori kurang baik. Dari 10 orang anak asuh 7 anak asuh berada pada ketegori kurang baik dan 3 anak asuh berada pada kategori cukup baik. Hasil ini bisa dijadikan sebagai dasar bagi pembina anak asuh untuk memberikan intervensi agar kemampuan penyesuaian anak asuhnya dapat ditinggkat. Melalui hasil ini banyak intervensi yang bisa diterapkan dan digunakan untuk meningkatkan penyesuaian sosial anak asuh dip anti asuhan.

\section{REFERENSI}

Danim, S. (2013). Perkembangan peserta didik. Bandung: Alfabeta.

Hartati, L., \& Respati, W. (2012). Kompetensi interpersonal pada remaja yang tinggal di panti asuhan asrama dan yang tinggal di panti asuhan cottage. Jurnal Psikologi Esa Unggul, 10(2), 79-86.

Hurlock, B. E. (2014). Perkembangan anak (6 Jilid I). Jakarta: Erlangga.

Irianto, A. (2010). Statistik konsep dasar dan aplikasinya. Jakarta: Predana Media. 
Khairat, I., Firman, \& Neviyarni. (2018). Efektivitas Pendekatan rational emotive behavior therapy (rebt) dalam meningkatkan penyesuaian sosial anak asuh. Mendidik: Jurnal Kajian Pendidikan dan Pengajaran, 4(2), 83-90.

Schneiders, A. A. (1964). Personal adjustment and mental health. New York: Library of Congress Catalog.

Sugiyono. (2014). Metode Penelitian kuantitatif kualitatif dan RED. Bandung: Alfabeta.

Sunarto, \& Hartono. (2013). Perkembangan Peserta didik. Jakarta: Rineka Cipta.

Sundari. (2005). Kesehatan mental dalam kehidupan. Jakarta: Rineka Cipta.

Surya, M. (2003). Teori-teori konseling. Bandung: Pustaka Bani Quraisy.

Syaputra, Y. D., \& Monalisa. (2018). Deskripsi Motivasi siswa untuk mengikuti konseling teman sebaya di SMA Negeri 1 Sungayang. Jurnal Bimbingan dan Konseling Terapan, 2(2), 156-167. 